\title{
The Dilemmas of Plastic Wastes in a Developing Economy: Proposals for a Sustainable Management Approach for Ghana
}

\author{
J. N. Fobil ${ }^{1 *}$ and J. N. Hogarh ${ }^{2}$ \\ ${ }^{I}$ School of Public Health, College of Health Sciences, P. O. Box LG13, University of Ghana, \\ Legon, Accra \\ ${ }^{2}$ Environmental Science, Department of Theoretical and Applied Biology, Faculty of \\ Biosciences, Kwame Nkrumah University of Science \& Technology, Kumasi, Ghana \\ *Corresponding author; jfobil@ug.edu.gh,jnhogarh.sci@knust.edu.gh
}

\begin{abstract}
Plastics have been used extensively in both food and water packaging because of their inherent properties such as low bulk densities and inertness that make them convenient carrier materials and low risk contaminants. Plastic bottles and sachets used to package iced water that is sold to people in transit points and in moving vehicles have become widespread in the sub-region. However, the packaging revolution has not been correspondingly backed by appropriate plastic waste management policy, which has left many cities in sub-Sahara Africa littered with plastic wastes; thus, creating disgusting visual nuisances and other public health problems. The paper discusses the experiences, challenges and prospects of plastic waste management schemes in Ghana and proposes a new model of fractional levy and polluter tax system to address this environmental eye sore. It is concluded that the current rate of environmental deterioration is likely to persist unless a long term remedial such as the polluter taxation system is carefully worked into plastic wastes management schemes in the region.
\end{abstract}

\section{Introduction}

Over the last few decades there has been a steady increase in the use of plastic products resulting in a proportionate rise in plastic waste in the municipal solid waste streams in large cities in subSahara Africa (World Bank, 1996; Yankson, 1998). The adoption of a more hygienic mode of packaging food, beverages, "iced water" and other products brought plastic packaging to replace the existing cultural packaging methods (leaf wrappers, brown paper and metal cup uses) in cities and towns (Adarkwa and Edmundsen, 1993; KMA, 1995; World Bank, 1995; Schweizer \& Annoh, 1996). This widespread replacement of the modes of packaging with plastics is an indication of the uniqueness of plastic properties such as versatility, inertness and flexibility, especially in the application areas of packaging. As a result of their unique properties, plastics have become the most favoured packaging materials in commerce with firms making windfall profits and transferring the environmental cost associated with cleaning plastic waste on the general public. Kreith (1994) suggested that the factors that tend to increase the per-capita and total amount of wastes as well as their constituents in waste stream include increased population, increased levels of affluence, changes in life style, changes in work patterns, new products, redesign of products, material substitution and changes in food processing and packaging methods.

Intense heat in the tropical and equatorial latitudes requires constant intake of water by the trekking populations during work hours and in market places. So it is a common observation in sub-Sahara Africa to find young people also trekking and selling iced water in trays or basins on their heads in public places and in the streets of cities and towns. Cooked food is also sold on the way side and in canteens or restaurants usually sited in open spaces near work places, offices, churches, markets and schools. The food is sold to passers-by who will usually accept the food wrapped in leaves, brown paper and/or plastics (Yankson, 1998). The packaging materials are most often dumped anywhere at the convenience of the trekking population since there is usually no mechanism that allows proper disposal of these materials after consumption of the cooked food. This gave rise to indiscriminate dumping of various materials ranging from leaf wrappers 
through paper to plastics. But paper and leaves easily degrade in the environment whilst the plastics do not.

In the past two decades, plastics have become the most favoured materials in food and water packaging industry and contributing to the large rise in their proportions in the waste streams in the region. Most countries in sub-Sahara Africa do not have data on waste stream composition, but individual management authorities recognise and acknowledge the growing magnitude and prominence of plastic waste problems in the region. In Nigeria, Federal agencies are still busy working to find the total per capita generation of plastics per day. In Mauritania, this has been done and documented. Waste composition studies are yet to be done in many sub-Sahara African countries so that knowledge of the amounts of various waste components would be gained. In many southern African countries including the Republic of South Africa, Madagascar, Lesotho, Botswana, Zambia, Zimbabwe and Angola, a lot of progress has been made in waste management in general, but detailed knowledge in the waste composition is lacking (World Bank, 1996). This is also the case with their counterparts in West and East Africa. In Ghana, for example, the percentage of plastics in the waste stream is $9 \%$ by weight shown in recent waste composition studies (Fobil, 2000).

\section{An overview of plastic use and plastic waste management in sub-saharan Africa}

It is a common phenomenon in many West African countries to have places where food and drinking water are sold to the general public cited in the open space. This is usually anywhere near offices, market places, public schools, churches and in any available open space in the central business districts (CBDs) within the cities. The most common of this kind of trade is that practised by vendors of drinking water and food who use walkways and pavements as the premises of their businesses to market their merchandise to people in moving vehicles.

In the late 1970s, it became apparent that easy spread of such food and water borne diseases as typhoid, cholera and dysentery in events of epidemics were intricately associated with these cultural practices in food and water industry. This discovery imposed a safety requirement on street vendors to institute new ways of food and water handling that would be safe and healthy so as to minimise the risk of disease episodes associated with the marketing of cooked-food and drinking water. The growing awareness in safe and proper modes of food packaging as well as increased need for more hygienic methods of handling drinking water to safeguard public health triggered off a decade of tremendous increase in the use of plastic products in West Africa.

However, packaging process dates back to medieval times when in those days packaging was perceived as a simple process of wrapping with leaves and tree barks. Historically, it has undergone considerable revolution over the centuries and trans-gressing from the simple process to more sophisticated industrial packaging technology today. Packaging finds application in all spheres of human endeavours, notably in food industries and in product transport. Various packaging standards exist, but the most fundamental requirement or goal of packaging is sustaining life span of the products that are packaged. In the food industry, an additional requirement of packaging is the maintenance of food products in wholesome and high hygienic conditions. In those olden days, food products were carried in leaves from markets and from commercial centres, in palm fronts and in banana leaves from farms in the rural areas. Until as late as in the $70 \mathrm{~s}$, leaves were still used as packaging materials in the sale of food by wayside food vendors in the major cities across the sub-region (KMA, 1995; Scheizer \& Annoh, 1996; Archer et al., 1997). Typical examples include the 'waakye' (mixture of cooked rice and beans) sellers and fishmongers who use leaves called "bede" (Thalia dealbata from the family Marantaceae) to wrap their products. Today, this mode of packaging is still common among many rural communities in West Africa. Over time, however, pressurised to lift food and water packaging standards by public health authorities, the business community switched to the use of paper as conventional packaging materials. Brown paper, with a common name "cement paper", 
was most preferred for use in packaging in Ghana as a consequence of its relative toughness and malleability, which made it easily modelled into cone shaped receptacles and used to carry food products such as "gari", fish, "kenkey" (local food made from maize flour), salt and many other variety of products.

Much later in the late 1980s and early 1990s the use of paper in conventional packaging gave way for polyethylene film bags and other plastics as stringent quality standards were required in food and water packaging industries so as to minimize the incidence of food and water related epidemics in the region. Several properties of polyethylene films make them unique and give them comparative advantage over the other packaging materials such as leaves and paper that were previously in use. They are lightweight, tough with low bending to rigid properties, inert and relatively un-reactive. These properties make them more convenient as carrier and hygienic packaging materials as compared to paper and leaves. Utilised basically in the iced water business initially, their application in the packaging industry was adopted in a variety of other areas such as food and beverages packaging, groceries, pipelines for potable water supply, construction and agriculture. Indeed, their application is widespread in West Africa and highly demanded in practically all sectors of human activity across West Africa. Their use in iced-water business replaced the more primitive ways of iced-water sale, through multiple use of cups by several people, which was a major source of spread of most epidemics. Proliferation of plastic materials addressed the health issues relating to food and water packaging, but it also created the problem of plastic waste in the region.

In Ghana, per capita generation of plastic wastes stands at $0.016-0.035 \mathrm{~kg} / \mathrm{person} / \mathrm{day}$, and plastics make up between $8-9 \%$ of the component materials in the waste stream (Fobil, 2000). Now most products are packaged in polyethylene films, which form about $70 \%$ of the plastic waste in the municipal waste stream. According to Fobil (2000), the plastic materials in commerce across the sub-region include low-density polyethylene (LDPE) commonly called polyethylene films, high-density polyethylene (HDPE) and other plastics such as polypropylene, polystyrene, polyvinyl chloride (PVC) and polyethylene terephthalate (PET).

The analysis of the historical trend of plastic waste composition in the waste stream in Ghana shows that in 1979 the percentage by component was $1.4 \%$ and by 1993 it had risen to 4\% (Schweizer \& Annoh, 1996). In 1996/97, the proportion of plastic waste in the waste stream was 5\% (Schweizer \& Annoh, 1996; Archer et al., 1997) and by 1999/2000 its proportion increased to $8 \%$ (Fobil, 2000). This was a consequence of huge profits from the sale of plastics and the existing large domestic market, propelling private enterprises to begin to commit huge capital into plastic industry, and, by 1996, there were about 20 plastic producing establishments in Ghana. This included those of plastic films, with notable ones such as Poly Products, PolyTank and Sintex (Adarkwa \& Edmundsen, 1993; Archer et al., 1997; Accra Sanitation Workshop, 1998; Agyenim-Boateng, 1998). By the turn of this century, it was reported that there were about 40 plastic manufacturing companies producing about 26,000 metric tones of assorted plastic products annually in Ghana, with $90 \%$ of the companies in the Accra-Tema Metropolitan Area. Additionally, over 10,000 metric tones of finished plastic products are imported annually into Ghana (Fobil, 2001).

\section{Effects of plastic littering in Ghana}

The plastic wastes have virtually choked the drainage system in the urban centres of the country to such an extent that it takes only the slightest of rainfall to precipitate floods in major cities like Accra, Kumasi and Takoradi. Indeed, as captured in the Daily Graphic of March 16, 2005, "the recent rains in Accra exposed the havoc being caused by plastic waste. Just an average of one or two hours of rain in Accra on March 15, 2005 led to flooding in certain parts of the city. The same intensity and duration of rain, a decade ago, would not have resulted in flooding". Although different factors, such as erection of buildings and structures in water courses, have 
contributed to the increased incidence of flooding, lately, the significant cause of flooding in cities in Ghana is linked to the tremendous deterioration in urban drainage systems, most of which is attributable to plastic wastes blocking the drainage systems. How can we remove the plastic wastes from our urban environment and keep our drainage system clear of plastics?

\section{Earlier plastic waste management initiatives in Ghana}

The sharp increase in quantities of plastic materials in the waste stream from $1.4 \%$ to $8 \%$ in about a 21-year period had begun to have serious environmental consequences as planning authorities had not factored into waste management programmes facilities to handle these materials. This resulted in a significant visual pollution of the urban environments. Plastics do not easily degrade in the environment by natural biological processes and tend to persist for longer periods of time than leaves and paper materials. Additionally, the disposal culture of plastic consumer public has been irresponsible and proper disposal interventions have been weak and unable to address the plastic load in waste streams in the cities (Archer et al., 1997; Agyenim-Boateng, 1998; Accra Sanitation Workshop, 1998; Yankson, 1998). The result of the laxity of proper plastic waste disposal is the plastic waste everywhere in the major cities. Drainage channels and waterways, which are usually open-drains, have become choked with these plastics, forcing urban storm water to overflow the banks of drainage channels causing destructive floods in the cities.

The problem called for great concern among waste managers, urban planners, politicians, public health workers and the general public, with several unsuccessful attempts to arrest the trend in the past decade. In the past 5 years, renewed discussions on correcting the plastic waste problem have been on efficient and sustainable intervention schemes to minimise and arrest the adverse effects of plastics in the urban environments. It was in this light that in March 1996, a presidential committee was set up which charged the Industrial Research Institute (IRI) of the Council for Scientific and Industrial Research (CSIR) to explore the feasibility of the establishment of a plastic recycling programme in Ghana. The Institute came out with a report of its findings in October 1996 recommending that a pilot plastic recycling plant be set up in Pokuase, near Accra. A year later, a plastic waste management committee (PWMC) was set up on 20th August 1997 to augment the efforts of the Institute. The committee was drawn from nine agencies and institutions with interest in plastic wastes, including EPA-Ghana, Waste Management Department (WMD) of the Accra Metropolitan Assembly (AMA), Town \& Country Planning (TCP), Public Works Department (PWD), Ghana Standards Board (GSB), Ministry of Local Government and Rural Development (MLRD), Ministry of Health (MOH) and the private sector or NGOs (Accra Sanitation Workshop, 1998). The discussions among the groups gave birth to the plastic waste-recycling programme at Pokuase in Ghana through private sector initiative (Agyenim-Boateng, 1998; Accra Sanitation Workshop, 1998).

However, for the past 7 years since the onset of the plastic waste recycling programme at Pokuase in Ghana, the impact of the programme at mobilising plastics from the environment has hardly been felt. This is because plastic wastes continue to increase in Ghana's urban environment from year to year, despite the recycling programme that was put in place. There may be two explanations here, either the capacity of the recycling plant is too small to absorb all the plastics being generated or there is not any plastic waste collection programme sustainable enough to mobilise the plastics from the system and feed the recycling plant. There are arguments that more of the plastic waste recycling plants are needed in Accra to complement the current one at Pokuase. But with concerns that even the Pokuase plant is being under-utilised, the limitations in plastic waste management in the country may be pointing to the lack of sustainable plastic waste collection in the country.

Recent Government response 
Realising the need for some structured plastic waste collection process for addressing the plastic waste menace in the country, the Ministry of Tourism and Modernisation of the Capital City together with the Accra Metropolitan Assembly proposed that plastic waste producers in the city of Accra should bear the cost of collection of the plastics, declaring a levy of 11,000 Ghanaian cedis (about 1.2 US dollars) per kilogram of plastic raw material. The Ghana Plastic Manufacturing Association (GPMA) has however rejected this levy, citing, among other things, the following critical issues:

- that the issue of plastic litter on the streets is not restricted to only Accra, but it is a national issue whose solution demands a holistic approach to cover every city, town and village;

- that litter results from aberrant consumer behaviour and irresponsible social attitudes and that solution must be geared towards the consumer as well;

- that imposing the same levy on all plastic raw material imports in total, without closely identifying and separating them into actual use of raw materials, is incorrect, since low density plastic materials constitute majority of the plastic wastes; and

- that many other non-plastic producing companies use plastic packages that are also indiscriminately disposed off on the streets, which need to be factored in as well.

It is clear that there is lack of policy direction with regard to sustainable plastic waste collection in Ghana. With no apparent headway in the plastic tug of war, government authorities at one point threatened to ban plastic manufacturing in the country if the GPMA members did not pay the proposed levy.

\section{Proposals for sustainable plastic waste collection in Ghana}

Fig. 1 illustrates fractional contribu-tions of all actors involved in the plastic production, distribution and utilisation chain-process to the burden of plastic waste pollution in developing cities. Plastic production, plastic retail and plastic use all contribute to the plastic littering in the environment. The quantity of plastic wastes each process node introduces into the environment is proportional to the strength and level of process-activities, which in turn has a direct bearing on the undertaking's marginal profit, i.e. the greater the activity level, the larger the profit margin. In principle, the only process-node that does not create plastic litter in the environment is the recycling node. Hence, the first choice of managing the plastic wastes is to recycle them. But this is not feasible, in the absence of local sustainable mechanisms for retrieving the plastic wastes from the environment.

Indeed, the lack of sustainable plastic waste retrieval process in Ghana is a major limiting factor to plastic waste management in the country. In this respect, a tax system for plastic waste collection in Ghana that would embrace all the actors indicated in Fig 1 is proposed. So far levy considerations on actors in plastic industry has been weak, as it has targeted predominantly the sachet water producers, who incidentally constitute only a small subset of all the actors in the plastic industry in Ghana. Hence, it is necessary that one looks wider and beyond to include all the other contributors to plastic pollution as a sustainable plastic waste retrieval mechanism is formulated, which anticipate the imposition of well-defined plastic pollution responsibility charges that equally target all plastic producers and retailers whose products litter the streets, as well as consumers of plastics or plastic users. This would constitute a more holistic approach to evenly distributing the local plastic pollution responsibility in a magnitude corresponding to pollution levels.

For instance, as the drainage system in Ghana is equally choked with plastics such as icecream wrappers, black polyethylene-film bags and other plastic materials, all producers of these products need to be made to bear well-calculated pollution responsibility in order to achieve a long-term solution to the plastic waste problem. Consumers of plastics and plastic products are also liable to pollution control charge since they are the terminal actors in the plastic pollution 
chain, who finally leave these plastic materials in the streets. There is a need to define a new scope of coverage and appropriately devise ways of making all actors in plastic pollution accountable for retrieving the plastic wastes from the surroundings. How can this be done? A suggestion of the way out in a model of tax system is offered as follows.

Given that any undertaking or activity that generates residuals into the environment and/or degrades the environment should contribute to environmental cleaning under the "Polluter-Pays" arrangement, such undertakings and activities have a social and corporate responsibility to contribute to a plastic collection and environmental cleaning tax fund (pollution responsibility charges). As such, for the retrieval of plastic wastes from the environment in Ghana, a plastic polluter pays (PPP) levy system is advocated. This calls for an appropriate incremental levy system (perhaps per kilogram of plastic) that takes into account the margin of plastic pollution to be placed on all actors.

A weighted proportion of the levy should be borne by producers of the plastics (production pollution levy) and a correspond-ing weighted proportion also borne by the consumers who patronise the plastics or plastic packaged products (consumption pollution levy). Under this incremental levy system, it is possible to estimate the production capacity of the plastic producer and then calculate on monthly basis. This production pollution levy will be a fraction of its marginal profit and the quantity of plastics produced by the producer, which then can return into the environment to cause environmental pollution, if uncollected. Now, consumers of plastic products incur consumption pollution charges by buying plastics or plastic packaged products. This will be a certain percentage of the production pollution charges calculated based upon the rate of consumption. The consumer PPP levy is meant to instil discipline in consumers regarding the way they dispose off plastics and this levy is retrievable by the consumer based on a tax refund system (or cash-back), which is part of the proposed levy system.

The administration of the PPP levy system would be such that several plastic collection points are set up in various towns and cities across the country. This should give plastic consumers or thrash pickers an opportunity to be given cash back when they return plastic wastes to any of these points. Cash back may be dependent on a kilogram of plastic returned or any other acceptable calculation. It should be convenient for the populace to reach these plastic collection points, which can be established both in residential and commercial places, as well as in some supermarkets. In this case, when one drinks, for instance sachet iced-water, there is financial motivation to keep the sachets and return them in exchange for cash-back on the product.

Similarly, people would be encouraged to return their black plastic carrier bags to the collection points for some cash back. Otherwise, anybody who collects plastic wastes from the floor and takes back to the collection point would enjoy the corresponding cash back. If the plastic wastes are not returned to the collection point, then city/town authorities have the responsibility to use the consumer PPP levy on the plastics to pay scavengers to collect these wastes from the corridors of the cities and towns. In effect consumers of plastic products would bear a portion for the collection of the plastic wastes. The consumers, however, have the choice not to bear this levy when they return the plastic waste to the collection point. This kind of system has already proven to work informally in many cities in sub-Sahara Africa as some lowincome groups often pick-up potentially useful waste materials from the curbside for resale to the public.

As shown in the theoretical model in Fig. 1, the pollution responsibility charges (see arrows in Fig. 1) should result in a consoli-dated plastic waste cleaning fund, which, if properly managed, should be large enough to offset the cost of plastic collection and recycling. There should be a well defined set of guidelines for the application of such a fund for purposes of plastic waste management so as to avoid inherent embezzlement and misapplication of the fund. 


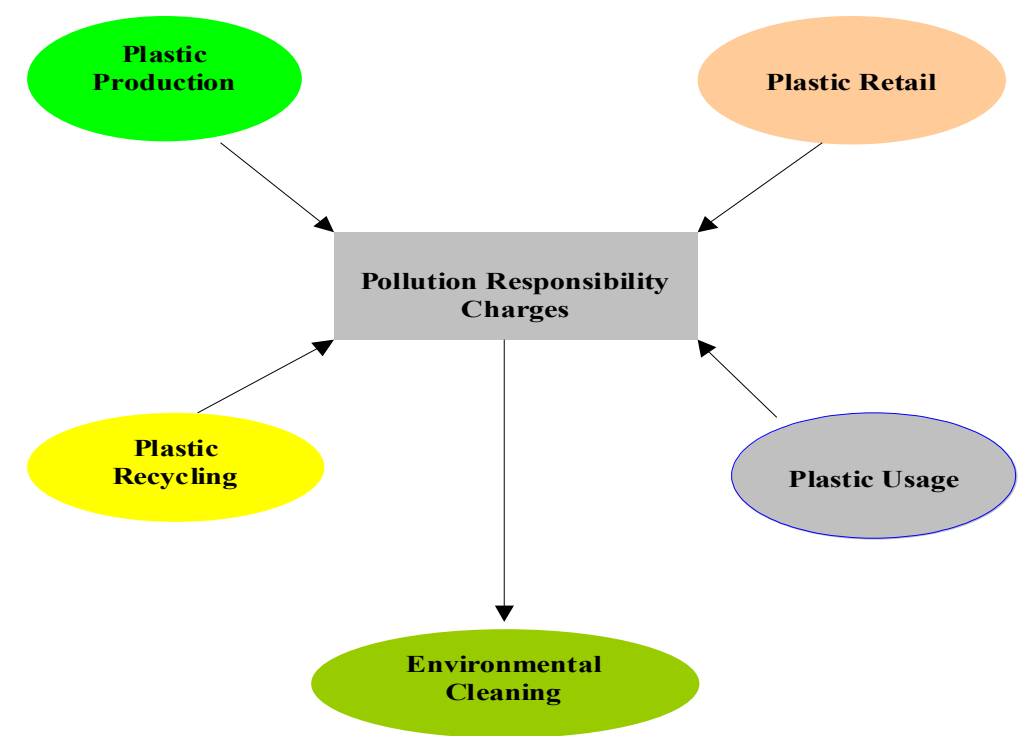

Fig. 1. Proposed tax system for plastic wastes collection scheme in Ghana

\section{Conclusion}

In principle, the proposed PPP levy system spreads the responsibility of management of plastic waste among three key stakeholders: the producers of the plastics (those with high propensity of ending up as litters), the consumers of the plastics and the appropriate authorities responsible for plastic waste management. The concept is to be able to create direct value in plastic wastes such that people will be willing to collect them from the ground. Most waste scavengers in Accra, for instance, would quickly pick up metallic waste because locally it has ready market value; they are locally recycled into coal-pots, metallic cooking pots and many other useful metallic equipment or utensils. Bottles are also limited in the waste stream because they are picked up and resold mostly for reuse. It is, therefore, envisaged that if market value could be created in plastic waste, scavengers would start picking them as well. It is concluded that itinerant waste buyers would start moving from house to house to buy plastic waste.

\section{References}

Accra Sanitation Workshop (1998). Report of the Discussion Group on Financing and Cost Recovery Options. AMA, Accra.

Adarkwa K. K. and Edmundsen A. R. (1993). Urban Waste Management in Ghana, a Study of Eleven Urban Centers. University of Science and Techno-logy, Kumasi.

Agyenim-Boateng K. (1998). Solid Waste Management: Background and Approach to Private Sector Participation. MLRD Publication, Accra.

Archer E., Larbi B. and Anim A. (1997). Privatization of Refuse Management in Atonsu, Kumasi, Ghana. Research Papers No. 7, University of Science and Technology, Kumasi and University of Amsterdam, Amsterdam.

Fobil J. N. (2000). Municipal Solid Waste Characterization for Integrated Management in the Accra Metropolis, (MSc. Thesis.), University of Ghana, Legon, Accra.

Franzen A. (1997). Privatization of Public Toilets in Kumasi, Ghana. Research Papers No. 8, University of Amsterdam, Amsterdam.

KMA (1995) Strategic Sanitation Plan for Kumasi 1996-2005. Kumasi, Ghana.

Kreith F. (1994). A Handbook of Solid Waste. McGraw-Hill, New York.

Schweizer F. and Annoh C. K. (1996). Privatization of Solid Waste Management in Ghana, Trialog 48: 50.

World Bank (1995). Ghana, Growth, Private Sector, and Poverty Reduction, a Country Economic Memorandum. Washington D.C.

World Bank (1996). Urban Environmental Sanitation Project, Staff Appraisal Report, Republic of Ghana, Africa Regional Office. 
Yankson P. W. K. (1988). The Urban Informal Economy Accommodation, Growth, Linkages, Health and Environmental Impact. The Case of Greater Accra Metropolitan Area (GAMA). Ghana University Press, Accra. 